\title{
CUBA: A FORMAÇÃO DOS PROFESSORES DO CURSO DE PEDAGOGIA
}

Drielly Adrean Batista, Alonso Bezerra de Carvalho

Universidade Estadual Paulista - UNESP, Programa de Pós - Graduação, Marília, SP. E-mail: driellyadrean@yahoo.com.br

\section{RESUMO}

O presente artigo aborda a formação dos professores em Cuba, de forma a considerar alguns aspectos, como: a formação dos docentes de Pedagogia, a estrutura pedagógica, a organização curricular e o perfil do formador. Este trabalho busca, assim, empreender uma reflexão acerca da formação dos docentes em Cuba. A formação dos professores tem sido muito discutida nos últimos anos, assim como seus problemas e suas possíveis mudanças. Os questionamentos dos docentes e suas inquietações nos levaram a pensar em possíveis mudanças, a fim de refletir sobre a formação dos professores, em especial os do curso de Pedagogia. Finalmente, esperamos ter contribuído para o desenvolvimento de um novo olhar sobre a educação, de maneira a estimular uma reflexão sobre aspectos importantes no que diz respeito à realidade na formação dos professores no Brasil.

Palavras-Chave: Educação, Formação de professores, Teoria, Prática, Cuba

\section{CUBA: THE TRAINING OF THE TEACHERS OF THE PEDAGOGY COURSE}

\begin{abstract}
The present work deals with the training of teachers in Cuba, in order to consider some aspects, such as: teacher education, pedagogical structure, curricular organization and teacher profile. This work seeks to undertake a reflection on the training of teachers in Cuba. The training of teachers has been much discussed in recent years, as well as their problems and their possible changes. The questioning of teachers and their concerns led us to think about possible changes in order to reflect on the training of teachers, especially those in the Pedagogy course. Finally, we hope to have contributed to the development of a new perspective on education, in order to stimulate a reflection on important aspects regarding the reality in the training of teachers in Brazil.
\end{abstract}

Keywords: Education, Teacher Training, Theory, Practice, Cuba 


\section{INTRODUÇÃO}

A formação de professores, cuja base é o ensino universitário, tem sido um assunto muito importante nos dias atuais.

Cuba é uma referência quando se fala sobre a formação de professores, sua estrutura curricular, a organização dos cursos de licenciatura e a prática docente.

Para o autor Oliveira (2007, p. 41):

Cuba está localizada na parte insular da América Central. região conhecida como Antilhas. 0 arquipélago é formado por mais de 1600 ilhas e ilhotas, com aproximadamente $105 \mathrm{mil} \mathrm{km}^{2}$ de extensão. Por estar na entrada do golfo do México, o arquipélago fica próximo da América do Norte, mais precisamente dos Estados Unidos da América, do mar do Caribe e da Jamaica, e também do Haiti.

Em Cuba, de acordo com a OEI ${ }^{1}$ (Organização dos Estados Ibero-americanos) há dois tipos de Órgãos de Estado: os Órgãos superiores de Poder Popular e os Órgãos Locais de Poder Popular.

De acordo com Freitas (1998, p. 2016):

O sistema educacional cubano se apóia [sic] nos princípios de carássivo da educação; no princípio da vinculação estudo da educação; no princípio da participação de toda a sociedade nas tarefas da educação do povo; da co-educação [sic] e no princípio da gratuidade do ensino em todos os níveis.

A estrutura do ensino é organizada da seguinte maneira: Círculo Infantil (zero a quatro anos de idade); Pré-escolar (cinco anos), Escola Primária (6 a 11 anos); Secundária Básica (12 a 14 anos); Pré-universitária; Escolas de Ofícios, Secundária, Obrero-campesina e Instituto Politécnico (15 a 17 anos); Universidades e Centros Universitários e Institutos Superiores. Para os alunos que não conseguem atingir o nível superior, há o chamado "Programa de Superação".

A organização do governo, voltada para o ensino unificado, é constituída por oito ministérios, um escritório, um comitê e um instituto nacional. O Ministério da Educação Superior é o responsável pelas faculdades de formação que atuam na área educacional.

A formação de professores em Cuba, desde a Educação Infantil ao Ensino Universitário, é constituída por cursos de licenciatura plena de nível superior, os quais estão sob total responsabilidade do Estado. Todos os cursos de licenciatura são de período integral, têm duração de 5 anos e uma ampla ligação entre a universidade e a escola (teoria e prática). Outro aspecto relevante do curso de Pedagogia em Cuba é o diagnóstico integral do aluno que está iniciando o curso de licenciatura, por meio da qualificação de cada perfil do discente.

O currículo do curso de Pedagogia está organizado, primeiramente, pelo caráter teórico intensivo, com o objetivo de trabalhar aspectos psicológicos, pedagógicos e sociológicos. No segundo ano, os estudantes já são encaminhados às escolas denominadas "microuniversidades", que são sedes universitárias criadas para atender os alunos de Pedagogia. Isso estabelece, desde cedo, uma relação entre prática e pesquisa. "En la escuela tiene lugar la interacción de los maestros que se forman con los docentes de experiencia ya en ejercicio"(MARIÑO SÁNCHEZ et al., 2004, p. 6-9).

Os professores universitários do curso de Pedagogia recebem uma formação pedagógica na própria instituição em que atuam. Durante essa formação, os docentes são preparados para lecionar no mencionado curso e para colocar em prática os saberes a eles transmitidos, tendo sempre em mente que o objetivo da Educação Superior cubana, nos cursos de licenciaturas que formam professores, é articular a teoria com a prática desde o princípio.

Em 2006, a Orealc, ${ }^{2}$ juntamente com a Unesco, declararam Cuba como exemplo de excelência na educação. Esses órgãos consideraram que o alto desempenho cubano em termos de

\footnotetext{
${ }^{1}$ A OEI é um organismo internacional de caráter governamental cujo objetivo é a cooperação entre os países ibero-americanos nos campos da educação, da ciência, da tecnologia e da cultura, dentro do contexto do desenvolvimento integral da democracia e da integração regional.

${ }^{2}$ Orealc é a sigla da Oficina Regional da Educação para América Latina y el Caribe. Exerce uma missão de conhecimento da educação, juntamente com os direitos humanos durante toda sua existência.
} 
educação se deve à qualidade na formação dos professores. De acordo com Castro (1999), que aborda a formação dos professores em Cuba:

Os professores cubanos são contratados por 40 a 44 horas por semana e espera-se que ensinem de 16 a 20. São reservadas, portanto, 20 horas para preparar as aulas e interagir com os alunos. As salas de professores estão disponíveis para estas atividades extra-classe. (CASTRO, 1999, p. 344).

Para atingir a mencionada excelência no ensino, desenvolvem-se e preveem-se programas educativos e sociais de curto e de longo prazos, a fim de eliminar as barreiras que reprimem spirações e para aumentar as oportunidades e as possibilidades de cada criança, adolescente, jovem e adulto quanto ao acesso à educação e à cultura.

É preciso mencionar, neste ponto, que a introdução que se fez acima exigiu um caminho metodológico que será descrito a seguir.

\section{METODOLOGIA}

A presente pesquisa é de cunho qualitativo, uma vez que objetiva interpretar um determinado fenômeno com base na observação, na descrição, na análise e na compreensão.

A investigação qualitativa, conforme afirmam Lessard-Hérbert, Goyette e Boutin (1994), parece dar lugar ao contexto da descoberta antes e durante o levantamento dos dados; ou seja, de acordo com os três mencionados autores, as hipóteses e as questões não estão totalmente formuladas no início da pesquisa.

A presente pesquisa desenvolveu-se em três fases: a primeira recorreu a uma seleção de autores para a realização da pesquisa, bem como a escolha de sites e revistas, todos empregados para obter um embasamento teórico. A segunda etapa dirigiu-se à verificação das informações já selecionadas e à leitura de todo o conteúdo teórico para a conclusão da pesquisa. Por último, a terceira fase empreendeu, após uma leitura atenciosa, uma análise dos dados, ou seja, a escrita de todo o embasamento teórico obtido por meio da leitura dos livros, artigos, sites e revistas.

Enfim, toda essa trajetória foi e extrema importância para a realização da reflexão proposta como finalidade deste trabalho.

\section{RESULTADOS E DISCUSSÃO}

No Brasil há uma ênfase na construção social do professor como um ser social crítico e um agente transformador da sociedade. Outra diferença está na indagação: como se dá a formação desse aluno que será um futuro professor. Ele realmente quer ser professor? Ou somente está cursando Licenciaturas ou Pedagogia por falta de opção?

Quanto às relações referentes a tal desinteresse, aparece, em primeiro lugar, a desvalorização do profissional perante os governantes e a sociedade; em segundo, figura a remuneração injusta dos docentes; em terceiro, é mencionada a sobrecarga da função do professor, que, em decorrência de sua má remuneração, leva o docente a dobrar sua carga horária para ter um salário maior.

No caso específico de Cuba, conforme as informações obtidas, o estudante de Pedagogia tem um perfil específico, e toda a sua formação está voltada para a formação de um professor competente, que analisa teorias, exerce uma reflexão a respeito da prática de suas ações e faz uso de determinadas teorias para resolver os conflitos encontrados no dia a dia, tornando-se um docente reflexivo. No sistema cubano, desde a estruturação do programa até a percepção do aluno futuro professor, distingue-se uma outra visão acerca da educação: a forma como o currículo é apresentado, o diagnóstico que esse estudante recebe (se realmente há um perfil para o "ser professor") e a prática como elemento essencial para a complementação dessa formação. A remuneração do profissional da educação de Cuba é igual à dos outros profissionais, como médicos, engenheiros e enfermeiros.

Em 1991, Libâneo fez algumas considerações importantes sobre os reducionismos das novas 
experiências na formação de educadores.

O esfacelamento dos estudos no âmbito da ciência pedagógica, com a consequente subjunção do especialista no docente, e a improcedente identificação dos estudos pedagógicos a uma licenciatura, talvez sejam dois dos mais expressivos equívocos teóricos e operacionais da legislação e do próprio movimento da reformulação dos cursos de formação do educador, no que se refere à formação do pedagogo. (LIBÂNEO, 1991, p. 115).

Libâneo considera a Pedagogia uma área de conhecimento relacionada com a realidade. Ele considera o pedagogo um profissional que articula os fatos, as estruturas, os contextos e as situações com sua prática educativa. Assim, a relação entre a teoria e a prática tem papel fundamental para a construção da qualidade na Formação dos Professores.

\section{CONCLUSÃO}

Considerando o objetivo do presente trabalho, isto é, realizar uma reflexão sobre a formação dos professores em Cuba, de maneira a apresentá-la como diversa da realidade atual da formação dos professores brasileiros, levantamos alguns questionamentos essenciais para uma consideração relativa a possíveis mudanças que seriam necessárias na formação do profissional da educação do Brasil.

A respeito da formação pedagógica no Brasil o que pode se dizer? Pesquisas nessa área surgiram nos anos 1990, e com isso houve a preocupação de estudar a sala de aula, a relação professor/aluno, como o conhecimento é transmitido e a grande área do ensino-aprendizagem. $\mathrm{E}$ a formação dos professores?

A formação dos professores no Brasil, nos cursos de licenciatura em geral, oferece disciplinas sociológicas, históricas e filosóficas na formação teórica. E o que se pode afirmar sobre a prática?

A ausência da prática na formação dos professores, vai, consequentemente, incidir na prática pedagógica diária desses docentes na sala de aula, sobretudo na aprendizagem dos alunos.

De acordo com a $\mathrm{ABED}^{3}$ no Sensu $\operatorname{EAD}^{4}$ (2016), o porcentual de alunos que estão à procura de cursos à distância está aumentando, e o curso de Pedagogia "on-line" apresenta um percentual de $25 \%$. Esse número cresce a cada ano, evidenciando a procura por cursos que formam professores à distância.

A formação continuada em Cuba funciona desde o primeiro semestre do curso de Licenciatura. A prática precede a teoria. Para o Sistema Educacional Cubano, o Professor é a ponte entre a prática e a teoria. Não é somente o ser intelectual, mas um alguém que representa o conjunto entre o afetivo, o moral, o emocional e o intelectual, sempre mediando a aprendizagem e levando o aluno a pensar por meio da prática.

O presente artigo serve, assim, como uma breve reflexão a respeito da real formação dos Professores no Brasil e do que seria necessário e possível fazer para obter uma melhora significativa no sistema educacional brasileiro, ou seja, a fim de preparar corretamente esse professor para as dificuldades que serão enfrentadas na sala de aula, de relacionar a teoria com a prática, de rever a estrutura curricular dos cursos de licenciaturas (especificamente os de Pedagogia) e de reconhecer o valor justo da profissão de educador.

\footnotetext{
${ }^{3}$ ABED: Associação Brasileira de Educação a Distância

${ }^{4}$ Sensu EAD (20

16): Relatório Analítico da Aprendizagem a Distância no Brasil
} 


\section{REFERÊNCIAS}

ABED. Associação Brasileira de Educação a Distância. Relatório Analítico da Aprendizagem a Distância no Brasil, $2016 . \quad$ Disponível em: <http://abed.org.br/censoead2016/Censo_EAD_2016_portugues.pdf>. Acesso em: 10 jan. 2018.

CASTRO, C. de M. Escolas feias, escolas boas? Ensaio, Rio de Janeiro, v.7, n.25, p. 342- 354, out.dez. 1999.

FONSECA, J. J. S. Metodologia da pesquisa científica. Fortaleza: UEC, 2002. (Apostila).

FREITAS, H. C. L. Formação de Professores na Escola Cubana: o processo nas séries iniciais. In: GOERGEN, P.; SAVIANI, D. (Orgs.) Formação de Professores: a experiência internacional sob o olhar brasileiro. Campinas, SP: Autores Associados; São Paulo: NUPES, 1998. p. 213-233.

HERNANDEZ, M. V. (org.). Sistema Educativo Nacional de Cuba. Capítulo 1. Educación y Sociedad. 1995. Disponível em: <http://www.oei.es>. Acesso em: 20 ago. 2017.

LIBANEO, J, C. A didática e as Tendências Pedagógicas. Série Ideias. São Paulo, FDE, 1991.

MARIÑO SÁNCHEZ, M. A.; SIERRA RICARDO, L.; LYVA SOLER, C. La Formación del profesor general integral: una experiencia de las universidades pedagógicas de Cuba. Anales del IV Congreso Internacional de Educación Superior - La universidad por un mundo mejor - Habana - Cuba, 2004.

OLIVEIRA, C. A. C. Geografia e ensino no Brasil e em Cuba: um estudo histórico-geográfico comparado. 2007. 267f. Tese (Doutorado em Geografia) - Faculdade de Filosofia, Letras e Ciências Humanas, Universidade de São Paulo, São Paulo, 2007.

SOUZA, J. F. A. Políticas de formação de professores para a Educação Básica: a questão da formação do formador no Brasil e em Cuba. Curitiba, 2007. 